\title{
Allocating Output Electricity in a Solar-Aided Coal-Fired Power Generation System and Assessing Its $\mathrm{CO}_{2}$ Emission Reductions in China
}

\author{
Jun Zhao ${ }^{1, *}$ and Kun Yang ${ }^{2}$ \\ 1 School of Humanities and Social Sciences, North China Electric Power University, Beijing 102206, China \\ 2 School of Economics and Management, North China Electric Power University, Beijing 102206, China; \\ yk@cec.org.cn \\ * Correspondence: zhaoj@ncepu.edu.cn
}

Received: 19 December 2019; Accepted: 13 January 2020; Published: 16 January 2020

\begin{abstract}
Coal-fired power generation in China is facing huge challenges due to its high share in the total electricity generation and its environmental problems. A solar-aided coal-fired power generation (SACPG) system, based on the integration of solar thermal energy into a conventional coal-fired power system, is an effective way to utilize solar energy and reduce coal consumption. The reasonable allocation of output electricity to solar energy and coal in a SACPG system and the evaluation of its $\mathrm{CO}_{2}$ emission reductions can help to acquire subsidies or financial support granted to renewable electricity and $\mathrm{CO}_{2}$ emission reductions. A methodology is proposed from the view of the technical characteristics of a SACPG system and the government regulation. The coal-to-electricity efficiency of the baseline unit or the coal-fired power system in a SACPG system is the key factor in the methodology, and it can be calculated on the basis of the norm of energy consumption of coal-fired power units in China. Then, the allocation of the output electricity to solar energy and coal can be calculated, and so can the $\mathrm{CO}_{2}$ emission reductions by the solar-coal hybrid system. Taking a $600 \mathrm{MW}$ SACPG system as an example, the methodology is further illustrated. The methodology can guarantee that the calculation of output electricity allocation in a SACPG system and the calculation of its $\mathrm{CO}_{2}$ emission reductions are accurate, conservative and transparent for its subsidies or financial support.
\end{abstract}

Keywords: solar-aided coal-fired power generation system; allocation and assessment methodology in solar-coal hybrid systems; solar energy integration; coal-fired power generation; $\mathrm{CO}_{2}$ emission reductions

\section{Introduction}

Coal-fired power generation will be the backbone of China's power sector for the foreseeable future [1]. By the end of 2018, the coal-fired power generating capacity in China was about 1008.35 gigawatts (GW) and it generated 4482.9 Terawatt/h (TWh), which account, respectively, for more than 53 percent of China's power infrastructure and almost 64 percent of the total power generation [2]. However, coal-fired power generation is under huge pressure due to its pollutant emissions and environmental problems. Based on the optimization of power unit structure, improving the efficiencies of coal-fired power units and increasing the shares of renewable energies in power generation are the important means for China's power sector to reduce pollution and greenhouse gas emissions [1,3].

Solar thermal energy is gaining much more attention as one of the renewable energies with the most potential, but its inherent deficiencies of low intensity and intermittency make a solar-alone power generation system costly to run and have negative effects on its large-scale application $[4,5]$. The integration of solar thermal energy into a conventional coal-fired power system, which is called a 
solar-aided coal-fired power generation (SACPG) system, may be one of the effective ways of utilizing solar energy and at the same time decreasing the coal consumption by the coal-fired power system. The large capacity and high parameters of the coal-fired power system in a SACPG system can make solar thermal energy be used more efficiently than that in a solar-alone power generation system. By sharing the power generation system with a coal-fired power system, the initial investment of the solar thermal power generation system can be reduced. In addition, a SACPG system can mitigate the hourly and diurnal variability of solar radiation, which has negative effects on the grid, through the variable load operation of its coal-fired power system. A SACPG system has two flexible operational modes, the power booster mode and fuel saving mode [6,7]. The power booster mode can be chosen for high power demand with the same amount of coal consumption, and the fuel saving mode for low power demand with the same power generation capacity.

A number of studies have been performed on SACPG systems with the integration of a parabolic trough collector into the coal-fired power system, mainly focusing on modeling and simulation, system integration and operating characteristics, and system optimization operation and strategies [6,8-13]. Based on the performance and technical characteristics of solar thermal power generation, the parabolic trough system and solar tower power system are more attractively suitable to be integrated with a coal-fired power system to build a SACPG system $[8,14]$. It has also been indicated that the performance of concentrating collectors may be less efficient than that of non-concentrating collectors in a SACPG system despite their higher solar thermal efficiency [15].

Some research studies have also been conducted on the cost and performance evaluations of SACPG systems from the view of the thermo-economic theory and the second law of thermodynamics [16-18]. However, these analyses cannot provide a foundation for the reasonable and clear allocation of output electricity in a SACPG system, which is the basis of the incentive policy-making for the solar-coal hybrid system. To gain fair access to subsidies granted to renewable electricity, several methods to allocate fractions of output electricity to different resources in a hybrid fossil-renewable power system were compared without the involvement of details of hybrid system integration technology [19]. However, these technical characteristics are important for the incentive policy-making to promote the integration of solar thermal energy into a coal-fired power unit.

Studies on the SACPG system have shown that it is a feasible, environmentally friendly and efficient power generation technology [14,20]. At present, the parabolic trough system has been commercialized among the solar thermal power generation systems [21], and the coal-fired power generation system is also a conventional and mature power generation technology. There are not many critical technical obstacles in the integration of solar thermal energy into a conventional coal-fired power generation system to build a solar-coal hybrid system. How to allocate the output electricity to solar energy and coal may be one of key factors which will financially influence the policies and measures for a SACPG system. According to the output electricity from different energy resources, fair incentive policies and measures can be made by government regulators, or existing relevant incentive policies and measures can be taken to promote the development of a SACPG system.

However, the comprehensive assessment of a SACPG system should include the integration of solar thermal energy, the dispatch conditions, its operation, and the operation of other power units in the grid to which the solar-coal hybrid system is connected, etc. The operational complexity of a SACPG system should be fully considered to allocate its output electricity and assess its $\mathrm{CO}_{2}$ emission reductions, along with the energy efficiency improvement of the hybrid system. A methodology of the output electricity allocation in a SACPG system and its $\mathrm{CO}_{2}$ emission reduction assessment can both simplify the relevant calculation and guarantee that the results are transparent, conservative and accurate, and can also provide incentives to improve the integration of solar thermal energy and the energy efficiency of the coal-fired power system in the hybrid system.

China has abundant solar energy and a high share of coal-fired power generation. A SACPG system is a promising generation technology to promote energy saving and emission reductions in China. In this paper, the allocation of output electricity to solar energy and coal will be studied 
from the view of the technical characteristics of a SACPG system and the government regulation. We begin in Section 2 by illustrating a SACPG system and analyzing the key issues about the output electricity allocation. In Section 3, we perform modeling analyses of the output electricity allocation in a SACPG system and its $\mathrm{CO}_{2}$ emission reductions, and the methodology is built. In Section 4 , the methodology and its application are further illustrated through a case study of a 600 MW SACPG system. We summarize the key points of the methodology and present the conclusions in Section 5.

\section{Description of a SACPG System and Key Issues for Output Electricity Allocation}

\subsection{Description of a SACPG System}

A SACPG system generally consists of two subsystems, a solar field subsystem and a coal-fired power system. A coal-fired power system is usually running in the regenerative rankine cycle with a steam-reheated process, in which some extracted steam from the turbine is used to preheat the boiler feedwater for improving the cycle thermal efficiency. The solar heat can also be used technically for steam superheating/reheating or air heating, etc. [22]. The heat energy absorbed from the solar field subsystem can be transferred to the coal-fired power system directly or via a heat exchanger.

The parabolic trough collector is the most mature way among all methods of solar thermal power generation [23]. Some commercial solar thermal power plants with parabolic trough collectors have already been constructed in the United States and Spain [24]. The parabolic trough collector is suitable for mid- and low-temperature solar-coal hybridization because of its technical characteristics such as temperature, flow control, system stabilization, cost, etc. [25]. The solar tower power system may be another potential choice for a SACPG system in the future due to its higher parameters (pressure and temperature) than that of the parabolic trough collector system [9]. Figure 1 illustrates the schematic diagram of a SACPG system, in which the coal-fired power system includes four low pressure heaters, three high pressure heaters and one deaerator. The solar energy from the solar field system can replace all or part of the extraction steam of feedwater heater $\mathrm{H} 1$, and the saved extraction steam can remain expanding in the turbine for power generation.

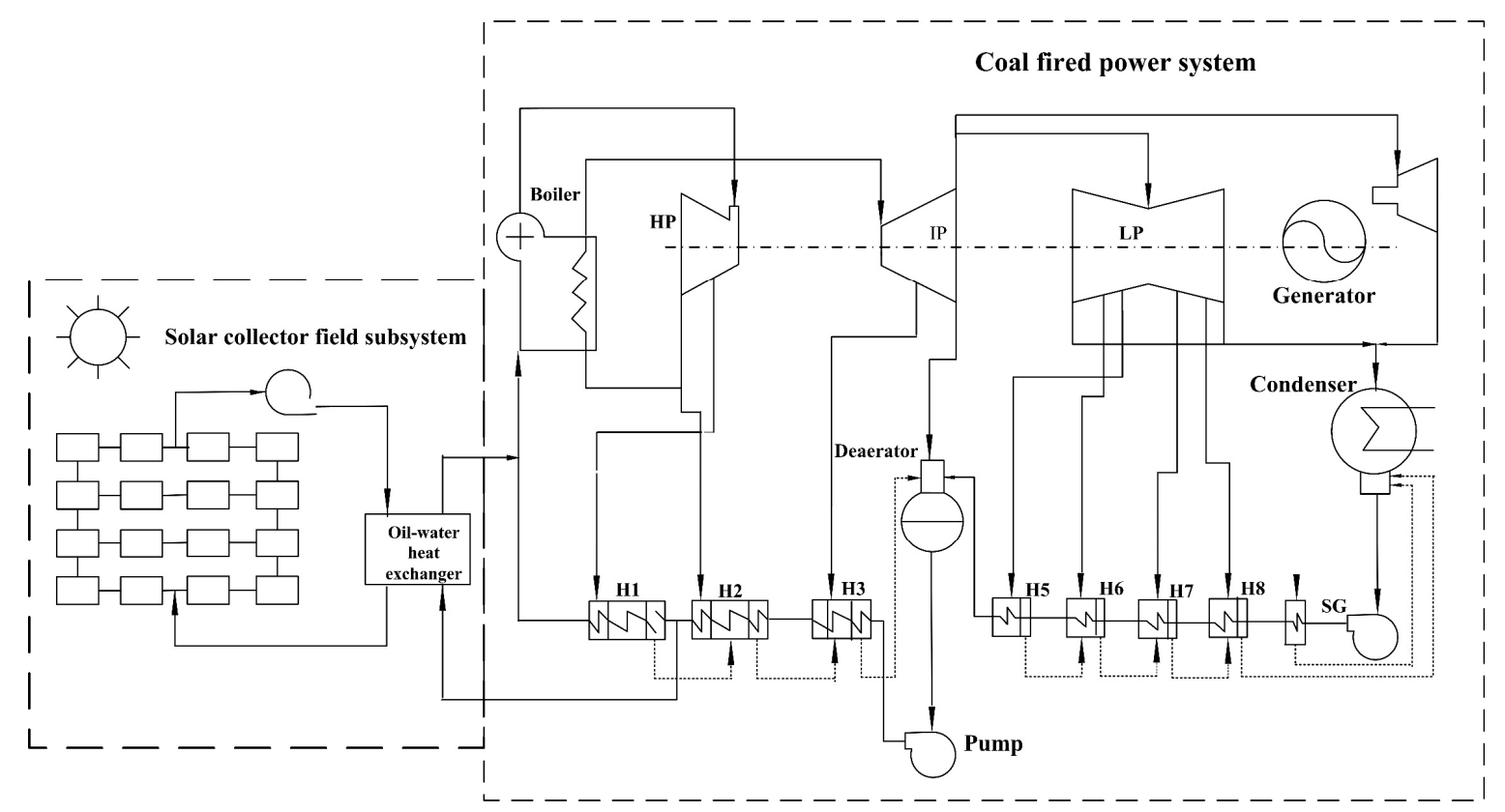

Figure 1. Schematic diagram for a solar-aided coal-fired power generation (SACPG) system.

\subsection{Key Issues for Output Electricity Allocation}

A SACPG system is affected by many factors, mainly including the efficiency of the solar field subsystem, solar radiation resources, the capacity and efficiency of the coal-fired power system, the load 
ratio of the hybrid system, the integration layout of solar energy, etc. So, the key issues for allocating the output electricity to solar energy and coal and assessing $\mathrm{CO}_{2}$ emission reductions in a SACPG system should focus on its operational complexity and system boundary, and also on the baseline scenario for its construction and operation.

\subsubsection{Analysis of the Operational Complexity of a SACPG System}

A SACPG system is a solar-coal hybrid system, and its overall efficiency $\eta_{S A C P G}$, can be defined in Equation (1) [16]:

$$
\begin{gathered}
\eta_{S A C P G}=\frac{3600 E G_{S A C P G}}{\left(M_{c} H+1000 Q_{\text {solar }}\right)} \\
Q_{\text {solar }}=Q_{a b s} \eta_{\text {soheat }} \\
E G_{S A C P G}=E G_{\text {solar }}+E G_{\text {coal }} \\
E G_{\text {coal }}=\frac{M_{c} H \eta_{c o, S A C P G}}{3600} \\
E G_{\text {solar }}=\frac{1000 Q_{a b s} \eta_{s o, S A C P G}}{3600}
\end{gathered}
$$

where $E G_{S A C P G}$ is the output power of the SACPG system, in $\mathrm{kWh} ; M_{c}$, is the amount of coal consumed by the SACPG system, in $\mathrm{kg} ; H$ is the lower heating value of standard coal, in $\mathrm{kJ} / \mathrm{kg} ; Q_{\text {solar }}$ is the output thermal energy from the solar field subsystem in the SACPG system, in MJ/h; $Q_{a b s}$ is the solar radiation absorbed by the solar field subsystem, in $\mathrm{MJ} / \mathrm{h} ; \eta_{\text {soheat }}$ is the efficiency of the solar radiation to the heat of the solar field subsystem; $E G_{\text {solar }}$ is the output power of the solar field subsystem, in $\mathrm{kWh} ; E G_{\text {coal }}$ is the output power of the coal-fired system, in $\mathrm{kWh} ; \eta_{C o, S A C P G}$ is the coal-to-electricity efficiency of the coal-fired power system; $\eta_{\text {solar, } S A C P G}$ is the solar-to-electricity efficiency of the solar field subsystem.

The design and operation of a SACPG system should depend on the solar radiation, the load rate of the hybrid system, and the coupling economic effect of the coal-fired system and solar field subsystem $[12,16]$. The output heat of the solar field subsystem in a SACPG system varies because of the intermittent solar energy. When no solar energy is integrated, the coal-fired power system in a SACPG system can be regarded as a conventional coal-fired unit. The coal-to-electricity efficiency of the coal-fired system in the hybrid system will change with the solar energy integration, and the unit can also be considered to run under off-design conditions. It is difficult to determine the output solar-to-electricity and coal-to-electricity in a SACPG system. However, the output electricity of a SACPG system, its operation hours and coal consumption can be easily recorded and measured.

Utilizing the solar energy and improving the efficiency of the coal-fired power system in a SACPG system are two different ways to reduce the coal consumption and pollutant emissions, and they have a coupling effect when solar energy is integrated. When the coal-to-electricity efficiency of the coal-fired power system is improved, the solar-to-electricity efficiency may increase. The solar-to-electricity efficiency improvement of the solar field subsystem will also have positive effects on the overall efficiency of the SACPG system. In addition, a SACPG system can balance the intermittent and volatile solar energy through the operation regulation of the coal-fired system, so it can reduce the reserve capacity of the grid to which the hybrid system is connected. The operation hours and output electricity of a SACPG system may increase due to the energy saving and low carbon power generation polices in China.

\subsubsection{The Boundary of a SACPG System and Its Baseline Scenario}

The operational complexity of a SACPG system makes it difficult to allocate the output electricity and evaluate its $\mathrm{CO}_{2}$ emission reductions. The transparent, conservative and accurate methodology of the output electricity allocation and $\mathrm{CO}_{2}$ emission reduction evaluation, which can help a SACPG system to obtain the support from the related fair incentive policies, has to be analyzed from the aspects of the boundary of a SACPG system and its baseline scenario, which is a reference scenario 
defined on the basis of the operation of power generation units in the grid to which the SACPG system is connected.

The baseline determination of a SACPG system involves its operational complexity, which may have an effect on the output electricity allocation and $\mathrm{CO}_{2}$ emission reduction assessment, and also on its financial and environmental validation. In order to simplify the complexity of the baseline determination, the boundary of a SACPG system can be defined according to its site and the grid to which it is connected, as shown in Figure 2.

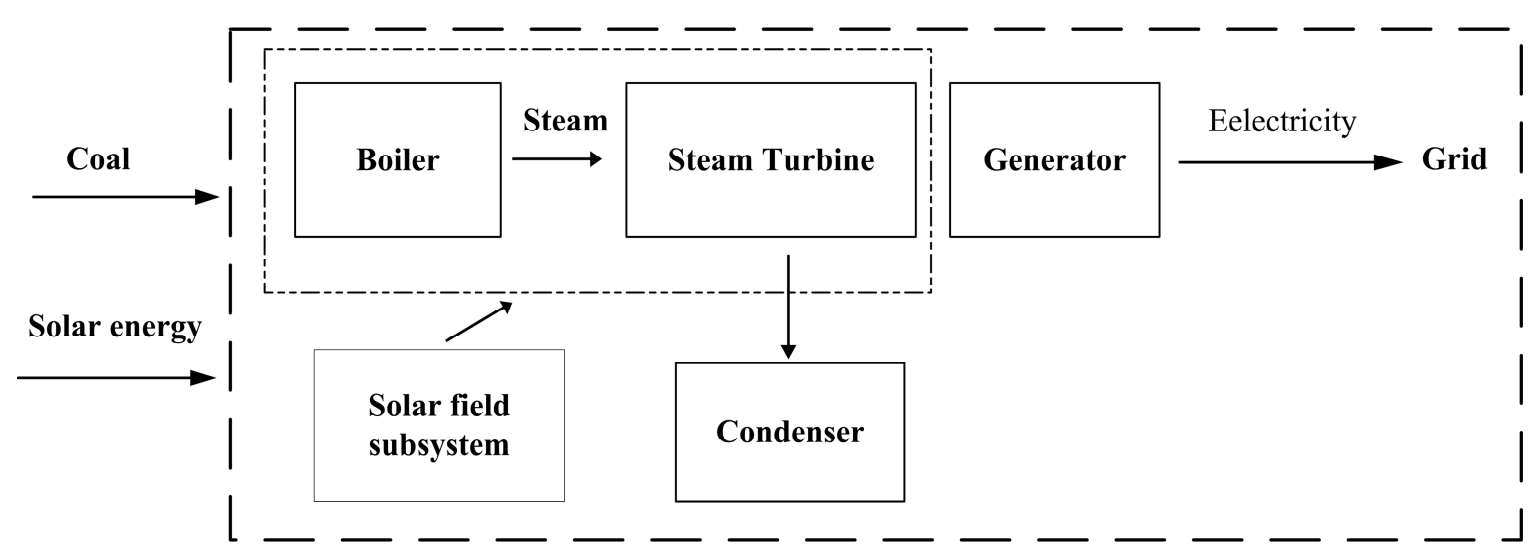

Figure 2. Conceptual diagram of the boundary for a SACPG system.

\section{Modeling and Methodology}

\subsection{Modeling of Output Electricity Allocation}

\subsubsection{Assumptions}

The solar energy in a SACPG system is taken as an aid to the operation of the coal-fired power system because the capacity of the solar field subsystem is usually smaller than that of the coal-fired system in the hybrid system. When the solar energy is integrated, the coal-fired power system may run under off-design conditions, which can result in a decrease in the efficiency of the coal-fired power system. The benefits from the solar energy integration will be offset by the efficiency change of the coal-fired power system. In order to indicate the overall effects of the integration on the performance of a SACPG system, the efficiency change of the coal-fired power system may be attributed to the solar field subsystem. It can be assumed that the efficiency of the coal-fired system is not affected by the integration of the solar energy, and the coal-fired system with no solar energy integration can be defined as the baseline unit for the SACPG system. The coal-to-electricity efficiency of the baseline unit, $\eta_{b r, s c a a l}$, can be defined in Equation (6).

$$
\begin{gathered}
\eta_{b r, s c o a l}=\frac{3600 E G_{S A C P G}}{M_{b r, s c o a l} H}=\frac{3600,000}{b_{b r, s c o a l} H} \\
b_{b r, s c o a l}=\frac{1000 M_{b r, s c o a l}}{E G_{S A C P G}}
\end{gathered}
$$

where $M_{b r, s c o a l}$ is the amount of standard coal consumed by the baseline unit, in $\mathrm{kg} ; b_{b r, s c o a l}$ is the standard coal consumption rate by the baseline unit, in $\mathrm{g} / \mathrm{kWh}$.

Therefore, the output electricity from the coal-fired system and the solar field subsystem can be, respectively, defined in Equation (8) and Equation (9) on the basis of the $\eta_{b r, s c o a l}$ and the annual power generation.

$$
\begin{aligned}
& E G_{c o a l, y}=M_{c, y} H \eta_{b r, s c o a l, y} / 3600 \\
& E G_{\text {solar }, y}=E G_{S A C P G, y}-E G_{c o a l, y}
\end{aligned}
$$


where $E G_{S A C P G, y}$ is the net output electricity of a SACPG system in year $y$, in $\mathrm{kWh}$; $E G_{c o a l, y}$ is the net output electricity of the coal-fired system in the SACPG system in year $y$, in $\mathrm{kWh} ; E G_{\text {solar, } y}$ is the net output electricity of the solar field subsystem in year $y$, in $\mathrm{kWh} ; M_{c, y}$ is the amount of standard coal consumed by the SACPG system in year $y$, in $\mathrm{kg} ; \eta_{b r, s c a a l, y}$ is the average coal-to-electricity efficiency of the baseline unit in year $y$.

According to the above analysis and Equations (8) and (9), $\eta_{b r, s c o a l, y}$ is the key factor to determine the allocation of the output electricity to solar energy and coal, for the net output electricity of a SACPG system and its coal consumption can be measured and recorded. However, the $\eta_{b r, s c o a l, y}$ is affected by many factors, such as the load ratio, the intermittency of solar energy, the off-design conditions of the coal-fired system, etc. In order to overcome the uncertain impacts of $\eta_{b r, s c o a l, y}$ on the output electricity allocation, it may be a good choice that $\eta_{b r, s c o a l, y}$ has to be authoritatively determined and regulated by the government sector [19], ensuring that the allocation method is transparent, conservative and accurate.

\subsubsection{Analysis and Determination of $\eta_{b r, s c o a l, y}$}

The determination of $\eta_{b r, s c o a l, y}$ has to be based on the capacity and other parameters (pressure and temperature) of the coal-fired power system in a SACPG system, its load ratio, etc., and the analysis approach for $\eta_{b r, s c o a l, y}$ is as follows.

(1) Determination of the rated standard coal consumption rate by the baseline unit

The capacity and the pressure of the baseline unit can be determined according to the relevant parameters of the coal-fired power system in a SACPG system. Then, on the basis of these parameters, the basic standard coal consumption rate by the baseline unit can be selected in the norm of energy consumption per unit product of general coal-fired power set [26], which is one of the standards of the People's Republic of China. The relevant data are shown in Appendix A. In addition, because the energy consumption of the baseline unit is also affected by its local temperature and cooling system, the modified coefficient for local temperature can be calculated by Equation (10) [26], and the modified coefficient for the cooling system can be selected from Table A2. The rated standard coal consumption rate by the baseline unit can be calculated by Equation (11).

$$
\begin{gathered}
m_{b t}= \begin{cases}1 & t \leq 5 \\
1+0.002 \times(t+5) & -5<t \leq 0 \\
1.01 & t>0\end{cases} \\
b_{r a, \text { coal }}=b_{s, \text { coal }} m_{b t} m_{b c o o l}
\end{gathered}
$$

where $t$ is the annual average temperature of the location of the SACPG system, in ${ }^{\circ} \mathrm{C} ; m_{b t}$ is the modified coefficient for local temperature; $m_{b c o o l}$ is the modified coefficient for the cooling system; $b_{r a, c o a l}$ and $b_{s, \text { coal }}$ are, respectively, the rated standard coal consumption rate and the basic standard coal consumption rate by the baseline unit, $\mathrm{g} / \mathrm{kWh}$.

(2) Calculation of the average load ratio of the SACPG system

Because the output electricity of a SACPG system, its operation hours and its coal consumption can be easily recorded and measured during the operation of the hybrid system, its average load ratio can be calculated by Equation (12).

$$
l_{\text {aver, }, \text { coal }, y}=\frac{E G_{S A C P G, y}}{C A P_{\max , c o a l} S h} \times 100
$$

where $C A P_{\text {max, gcoal }}$ is the maximum capacity of the coal-fired power system in the SACPG system, in $\mathrm{kW}$; $S h$ is the operation hours of the SACPG system in year $y$, in hours; $l_{\text {aver, coal, } y}$ is the average load ratio of the SACPG system in year $y$, in \%. 
(3) Determination of the average standard coal consumption rate by the baseline unit

The load ratio of the baseline unit in a SACPG system has an effect on its energy consumption. So, the modified coefficient for its average load ratio can be calculated by Equation (13) [26]. Based on the rated standard coal consumption rate by the baseline unit and the modified coefficient for its average load ratio, the average standard coal consumption rate by the baseline unit can be calculated by Equation (14).

$$
\begin{aligned}
& m_{b r, s c a a l, y}= \begin{cases}1 & l_{\text {aver, coal }, y} \geq 85 \\
1+0.0014 \times\left(85-100 \times l_{\text {aver, coal }, y}\right) & 80 \leq l_{\text {aver }, \text { coal }, y}<85 \\
1.007+0.0016 \times\left(80-100 \times l_{\text {aver,coal }, y)}\right) & 75 \leq l_{\text {aver, coal }, y}<80 \\
1.005^{\left(16-20 \times l_{\text {aver, coal }, y}\right)} & l_{\text {aver, coal }, y}<75\end{cases} \\
& b_{b r, s c o a l, y}=b_{r a, \text { coal }} m_{b r, s c o a l, y}
\end{aligned}
$$

where $m_{b r, s c a l, y}$ is the modified coefficient for the load ratio of the baseline unit in year $y ; b_{b r, s c o a l, y}$ is average standard coal consumption rate by the baseline unit in year $y$, in $\mathrm{g} / \mathrm{kWh}$.

(4) Determination of $\eta_{b r, s c o a l, y}$

According to the above analysis of $b_{b r, s c o a l, y}$ and Equation (6), $\eta_{b r, s c o a l, y}$ can be determined from Equation (15).

$$
\eta_{b r, s c o a l, y}==\frac{3600,000}{b_{b r, s c o a l, y} H}
$$

Therefore, when the $\eta_{b r, s c o a l, y}$ of the baseline unit is determined, the output electricity allocation in a SACPG system can be calculated by Equations (8) and (9), and $\eta_{b r, s c o a l, y}$ is the critical factor for the output electricity allocation. During the above analysis of $\eta_{b r, s c o a l, y}$, the data selected in the document, the norm of energy consumption per unit product of general coal-fired power set, are obtained authoritatively through the relevant statistical analysis of the operation of the coal-fired power units, and the data are also updated regularly by the relevant government sectors. A SACPG system may be built either from a coal-fired power unit with the integration retrofit of the solar energy before the SACPG system project starts, or from a new coal-fired power unit with the solar energy integration, and the relevant data for the calculation of the $\eta_{b r, s c o a l, y}$ of its baseline unit can also be selected in Appendix A to meet the requirements of the methodology.

If the actual coal-to-electricity efficiency of the coal-fired power system in a SACPG system is greater than the $\eta_{b r, s c o a l, y}$ of its baseline unit, part of the efficiency of the coal-fired power system is attributed to the solar field subsystem as a reward, increasing the output solar-to-electricity. If the actual coal-to-electricity efficiency of the coal-fired power system is not greater than the $\eta_{b r, s c o a l, y}$, there is no such a reward. Thus, the analysis method of $\eta_{b r, s c o a l, y}$ can encourage the coal-fired power system in a SACPG system to be retrofitted for the efficiency improvement, and also can encourage SACPG systems to be built in solar-rich areas.

\subsection{Modeling of $\mathrm{CO}_{2}$ Emission Reductions by a SACPG System}

Due to the solar energy integration, a SACPG system may consume less coal, resulting in $\mathrm{CO}_{2}$ emission reductions. The coal-fired power system in a SACPG system may be more efficient than other coal-fired units in the grid to which the solar-coal hybrid system is connected. The electricity generated by a SACPG system may replace part of the electricity generated by these coal-fired units, which can also lead to $\mathrm{CO}_{2}$ emission reductions. The $\mathrm{CO}_{2}$ emission reductions by a SACPG system can be calculated from Equation (16).

$$
E R_{S A C P G, y}=B E_{S A C P G, y}-P E_{S A C P G, y}-L E_{S A C P G, y}
$$


where $E R_{S A C P G, y}$ is the emission reductions by a $\mathrm{SACPG}$ system in year $y$, in $\mathrm{tCO}_{2} / \mathrm{y} ; B E_{S A C P G, y}$ is the baseline emissions for the SACPG system in year $y$, in $\mathrm{tCO}_{2} / \mathrm{y} ; P E_{S A C P G, y}$ is the $\mathrm{CO}_{2}$ emissions by the SACPG system in year $y$, in $\mathrm{tCO}_{2} / \mathrm{y} ; L E_{S A C P G, y}$ is the leakage emissions by the SACPG system in year $y$, in $\mathrm{tCO}_{2} / \mathrm{y}$.

\subsubsection{Determination of $B E_{S A C P G, y}$ for a SACPG System}

According to the above analysis, the $\mathrm{CO}_{2}$ emission reductions by a SACPG system will include the emission reductions from less coal consumption because of solar energy integration, and sometimes may also include the reductions from the displacement of electricity generated by less efficient units in the grid. There is some uncertainty about the reductions from the displacement of electricity. When the baseline emission factor for a SACPG system is greater than the emission factor of the grid to which the solar-hybrid system is connected, the reductions from the displacement of electricity will be included. Otherwise, this part of reductions will not be included and the reductions from the solar integration may be offset. Thus, in order to guarantee that the calculation of $\mathrm{CO}_{2}$ emission reductions is accurate, conservative and transparent, $B E_{S A C P G, y}$ can be calculated from Equation (17) [27].

$$
B E_{S A C P G, y}=E G_{S A C P G, y} \cdot \min \left(E F_{S A C P G, y} ; E F_{g r i d, y}\right) \cdot 10^{-3}
$$

where $E F_{S A C P G, y}$ is the $\mathrm{CO}_{2}$ baseline emission factor for a SACPG system in year $y$, in $\mathrm{tCO}_{2} / \mathrm{MWh}$; $E F_{\text {grid, } y}$ is the $\mathrm{CO}_{2}$ emission factor of the grid to which the SACPG system is connected in year $y$, in $\mathrm{tCO}_{2} / \mathrm{MWh}$.

\subsubsection{Calculation of $E F_{S A C P G, y}$}

The calculation of $E F_{S A C P G, y}$ is still based on the efficiency of the baseline unit in a SACPG system, $\eta_{b r, s c o a l, y}$, and it can be calculated from Equation (18).

$$
E F_{S A C G P, y}=\frac{3.6}{\eta_{b r, s c o a l, y} H} \cdot \gamma \cdot C_{c o 2}
$$

where $\gamma$ is the carbon proportion of standard coal; $C_{c o 2}$ is the conversion coefficient of carbon to $\mathrm{CO}_{2}$.

\subsubsection{Calculation of $E F_{\text {grid, } y}$}

The calculation of the $E F_{\text {grid, } y}$ of the grid to which a SACPG system is connected is complicated. It can be calculated according to the data in the documents about Chinese regional grid baseline emission factors, which are usually published by the Chinese government every year. The $E F_{\text {grid, } y}$ could be calculated according to Equation (19).

$$
\begin{aligned}
& E F_{\text {grid }, y}=w_{O M} \cdot E F_{\text {grid }, O M, y}+w_{B M} \cdot E F_{g r i d, B M, y} \\
& w_{O M}+w_{B M}=1
\end{aligned}
$$

where $E F_{g r i d, B M, y}$ is the build margin emission factor for the grid to which a SACPG system is connected in year $y$, in $\mathrm{tCO}_{2} / \mathrm{MWh} ; E F_{\text {grid, OM, } y}$ is the operating margin emission factor in year $y$, in $\mathrm{tCO}_{2} / \mathrm{MWh}$; $w_{O M}$ is the weight for $E F_{g r i d, B M, y}$; $w_{B M}$ is the weight for $E F_{g r i d, B M, y}$. Because solar energy is intermittent and non-dispatchable and less new coal-fired units are built, the weight of $w_{O M}$ should be increased and the weight of $w_{B M}$ be reduced, and $w_{O M}$ usually ranges from 0.5 and 1 [28].

\section{Case Study}

\subsection{Description of the Case and Assumptions}

In this section, a 600 MW SACPG system will be used to illustrate the methodology for the output electricity allocation and $\mathrm{CO}_{2}$ emission reduction evaluation. The SACPG system is located in Hohhot, 
Inner Mongolia in China, and its output electricity is fed into the North China regional power grid. The scheme of the SACPG system is shown in Figure 1, and the solar energy from the solar field subsystem will replace the extraction steam of feedwater heater H1. It is assumed that the SACPG system is built from an existing $600 \mathrm{MW}$ subcritical coal-fired unit (as shown in the right dashed line area in Figure 1), and that a LS-2 collector is used in the solar field subsystem. The key parameters of the hybrid system are shown in Tables 1 and 2. The efficiency of the LS-2 collector can be calculated from Equations (20) and (21) [29].

$$
\begin{gathered}
\eta_{\text {solar }, L S}=K_{\tau a} \cdot[73.3-0.007276 \cdot(\Delta T)]-0.496 \cdot\left(\frac{\Delta T}{I_{\text {direct }}}\right)-0.0691 \cdot\left(\frac{\Delta T^{2}}{I_{\text {direct }}}\right) \\
\Delta T=\frac{T_{o}+T_{i}}{2}-T_{a}
\end{gathered}
$$

where $\eta_{\text {solar, LS }}$ is the efficiency of the LS-2 collector; $I_{\text {direct }}$ is direct normal irradiation (DNI), in W/ $\mathrm{m}^{2}$; $T_{a}$ is the ambient temperature, in ${ }^{\circ} \mathrm{C} ; T_{i}$ and $T_{o}$ are, respectively, the inlet temperature and outlet temperature of the LS-2 collector, in ${ }^{\circ} \mathrm{C} ; K_{\tau a}$ is the incidence angle modifier factor.

Table 1. Key parameters of the coal-fired system in the SACPG system.

\begin{tabular}{ccc}
\hline Item & Unit & Value \\
\hline Capacity & $\mathrm{MW}$ & 600 \\
Main steam pressure & $\mathrm{MPa}$ & 16.7 \\
Main steam temperature & ${ }^{\circ} \mathrm{C}$ & 537 \\
Mass flow rate of main steam & $\mathrm{t} / \mathrm{h}$ & 1848.84 \\
Reheat temperature & ${ }^{\circ} \mathrm{C}$ & 537 \\
Feedwater temperature & ${ }^{\circ} \mathrm{C}$ & 274.1 \\
Exhausted steam pressure & $\mathrm{kPa}$ & 4.9 \\
Designed net coal consumption rate & $\mathrm{g} / \mathrm{kWh}$ & 322.9 \\
\hline
\end{tabular}

Table 2. Key parameters of the solar collector field subsystem in the SACPG system.

\begin{tabular}{ccc}
\hline Item & Unit & Value \\
\hline Designed direct normal irradiation (DNI) & $\mathrm{W} / \mathrm{m}^{2}$ & 800 \\
Inlet temperature of the solar field & ${ }^{\circ} \mathrm{C}$ & 247.2 \\
Outlet temperature of the solar field & ${ }^{\circ} \mathrm{C}$ & 280.1 \\
Solar collector field area & $\mathrm{m}^{2}$ & 148,140 \\
\hline
\end{tabular}

The efficiency of the LS-2 collector is affected by the change of DIN. The solar field subsystem will be bypassed due to less heat coming from it when the DIN is below a certain threshold value. The SACPG system will run as the original coal-fired power unit does without the solar heat integration. It is assumed that the threshold value of DIN is $300 \mathrm{~W} / \mathrm{m}^{2}$. The number of operating hours of the solar field subsystem under different DIN are shown in Table 3 from the statistics of solar energy resources in Hohhot, Inner Mongolia [30].

\begin{tabular}{|c|c|c|c|}
\hline DIN (W/m²) & Time (h) & $\operatorname{DIN}\left(\mathrm{W} / \mathrm{m}^{2}\right)$ & Time (h) \\
\hline 900 & 122 & 550 & 120 \\
\hline 850 & 122 & 500 & 302 \\
\hline 800 & 246 & 450 & 62 \\
\hline 750 & 122 & 400 & 244 \\
\hline 700 & 122 & 350 & 240 \\
\hline 650 & 306 & 300 & 308 \\
\hline 600 & 122 & & \\
\hline
\end{tabular}

Table 3. Distribution of DIN at Hohhot, Inner Mongolia in China. 
The $600 \mathrm{MW}$ unit has run for 10 years before the retrofit for solar energy integration, and its annual average operation time is about $4500 \mathrm{~h}$. It is assumed that the SACPG system would run in fuel saving mode and its operation hours would be increased to $7320 \mathrm{~h}$ because of the solar energy integration as well as the support from the energy saving and low carbon incentive polices and measures in China, and that the annual coal consumed by the hybrid system is about 1,142,594.9 ton. Then, the allocation of the output electricity by the SACPG system and assessment of its $\mathrm{CO}_{2}$ emission reductions in 2017 will be analyzed on the basis of the above methodology.

\subsection{Results and Discussions}

\subsubsection{Analysis of the Output Electricity Allocation}

According to the method in Section 3.1 and the grid to which the SACPG system is connected, the $\eta_{b r, s c o a l, y}$ of its baseline unit can be analyzed on the basis of the coal-fired power system in the solar-coal hybrid system. The local average temperature in Hohhot can be acquired from the China Statistical Yearbook, and the annual average temperature is always more than $0{ }^{\circ} \mathrm{C}$. The modified coefficient, $m_{b t}$, is 1.01 according to Equation (10). The cooling system of the SACPG system is a water cooling system, and the modified coefficient, $m_{b c o l}$, is 1.01 , which is selected from Table A2. Therefore, in accordance with the capacity of the SACPG system and its parameters, the basic standard coal consumption rate by the baseline unit can be selected from Table A1, and the standard coal consumption rate by the baseline unit can be calculated by Equation (14). The relevant data and results are shown in Table 4.

Table 4. Calculation of the standard coal consumption rate by the baseline unit.

\begin{tabular}{ccc}
\hline Item & Unit & Value \\
\hline$m_{b t}$ & - & 1.01 \\
$m_{b c o l}$ & - & 1.01 \\
$b_{s, c o a l}$ & $\mathrm{~g} / \mathrm{kWh}$ & 314 \\
$b_{r a, c o a l}$ & $\mathrm{~g} / \mathrm{kWh}$ & 320.3 \\
$l_{\text {aver,coal,y }}$ & $\%$ & 82 \\
$m_{b r, s c o a l, y}$ & - & 1.0042 \\
$b_{b r, s c o a l, y}$ & $\mathrm{~g} / \mathrm{kWh}$ & 321.7 \\
\hline
\end{tabular}

The rated standard coal consumption rate by the baseline unit in the SACPG system determined by the above method is $320.3 \mathrm{~g} / \mathrm{kWh}$, and this is lower than the designed net coal consumption rate of its coal-fired power system. The $\eta_{b r, s c o a l, y}$ of its baseline unit is higher than the actual coal-to-electricity efficiency of its coal-fired power system according to Equation (6), and this means that the output coal-to-electricity increases and the solar-to-electricity decreases, which may provide incentives to improve the efficiency of the coal-fired power system or the integration of solar energy, and even encourage the stakeholders to choose a coal-fired unit with high efficiency to build a SACPG system. If the standard coal consumption rate by its baseline unit determined by the above method is higher than its actual coal consumption rate, the solar-to-electricity increases and the solar-coal hybrid system may gain more benefits of the solar energy integration from the relevant policies and measurements for renewable energies.

The coal consumption rate determined by the above method is in line with the state of the art of a coal-fired power unit in China, and the relevant key data are shown in Table 5. According to the data on the net coal consumption of $600 \mathrm{MW}$ units, there may still be potential for the improvement of the coal-to-electricity efficiency of the coal-fired power system in the SACPG system. 
Table 5. Net coal consumption rates for coal-fired units on active duty [31] (unit: $\mathrm{g} / \mathrm{kWh}$ ).

\begin{tabular}{ccc}
\hline Coal-Fired Units & Average Level & Advanced Level \\
\hline 600 MW ultra-supercritical units & 298 & 290 \\
600 MW supercritical units & 306 & 297 \\
600 MW subcritical units & 320 & 315 \\
\hline
\end{tabular}

Based on the standard coal consumption rate by the baseline unit in the SACPG system, its average coal-to-electricity efficiency can be calculated. So, the output electricity, respectively, from coal and solar energy in the SACPG system can also be calculated from Equations (8) and (9). The results are shown in Table 6.

Table 6. The output electricity, respectively, from solar energy and coal in the SACPG system.

\begin{tabular}{lcc}
\hline \multicolumn{1}{c}{ Item } & Unit & Value \\
\hline$\eta_{b r, s c o a l, y}$ & - & 0.3821 \\
The effective DNI time & $\mathrm{h}$ & 2438 \\
Solar power generation & GWh & 47.781 \\
Coal power generation & GWh & 3552.219 \\
\hline
\end{tabular}

\subsubsection{Analysis of $\mathrm{CO}_{2}$ Emission Reductions}

The $\mathrm{CO}_{2}$ emission reductions from the SACPG system could be further calculated after its output electricity allocation is determined, and there are no leakage emissions in this case. The relevant data for the analysis of $\mathrm{CO}_{2}$ emission reductions are selected from the Chinese document of China's Regional Grid Baseline Emission Factors in 2017 [32], and they are shown in Table 7.

Table 7. Marginal emission factors of regional grids in 2017 (unit: $\mathrm{tCO}_{2} / \mathrm{MWh}$ ).

\begin{tabular}{lcc}
\hline \multicolumn{1}{c}{ Regional Grid } & $\boldsymbol{E F _ { \text { grid,OM,y } }}$ & $\boldsymbol{E F}_{\text {grid,BM,y }}$ \\
\hline North China Power Grid & 0.9680 & 0.4578 \\
Northeast China Power Grid & 1.1082 & 0.3310 \\
East China Power Grid & 0.8046 & 0.4923 \\
Central China Power Grid & 0.9014 & 0.3112 \\
Northwest China Power Grid & 0.9155 & 0.3232 \\
Southern China Power Grid & 0.8367 & 0.2476 \\
\hline
\end{tabular}

According to the method in Section 3.2 and the grid to which the SACPG system is connected, the baseline emission factors of the North China Regional Grid are selected, i.e., $E F_{\text {grid, } O M, y}=$ $0.968 \mathrm{tCO}_{2} / \mathrm{MWh}$, and $E F_{\text {grid, } B M, y}=0.4578 \mathrm{tCO}_{2} / \mathrm{MWh}$. Because the intermittent solar energy is integrated in the hybrid system and less new coal-fired units are built in the North China Power Grid [31], the weights of $w_{O M}$ and $w_{B M}$ are, respectively, set to 0.8 and 0.2 according to Equation (19). Then, the $\mathrm{CO}_{2}$ emission reductions can be calculated according to Equation (16), and the results are shown in Table 8.

Table 8. Calculation of $\mathrm{CO}_{2}$ emission reductions in the SACPG system.

\begin{tabular}{ccc}
\hline Item & Unit & Value \\
\hline$E F_{S A C P G, y}$ & $\mathrm{tCO}_{2} / \mathrm{MWh}$ & 0.8563 \\
$E F_{\text {grid }, y}$ & $\mathrm{tCO}_{2} / \mathrm{MWh}$ & 0.8659 \\
$B E_{S A C P G, y}$ & $\mathrm{tCO}_{2}$ & $3,082,500.56$ \\
$P E_{S A C P G, y}$ & $\mathrm{tCO}_{2}$ & $3,041,587.75$ \\
$E R_{S A C P G, y}$ & $\mathrm{tCO}_{2}$ & $40,912.81$ \\
\hline
\end{tabular}




\subsubsection{Further Analyses and Discussions}

It is through the determination of $\eta_{b r, s c o a l, y}$ that the allocation of the output electricity to different resources in a SACPG system can be calculated easily, and so can the $\mathrm{CO}_{2}$ emission reductions in the hybrid system. The calculation of the $\eta_{b r, s c o a l, y}$ of its baseline unit has to follow the procedure described in Section 3.1. The $b_{r a, c o a l}$ has to accord with the state of the art of a coal-fired unit, which can be indicated by the relevant data from Chinese government documents about Chinese regional baseline emission factors for new, grid-connected, fossil fuel-fired power plants using a less greenhouse gas (GHG)-intensive technology, or the coal consumption rates of coal-fired power units, etc. Besides, if there is still potential for the coal-to-electricity efficiency improvement of the coal-fired system in the SACPG system, $\eta_{b r, s c o a l, y}$ may be adjusted annually according to the relevant technical assessment reports or government documents, ensuring that the calculation is transparent, conservative and accurate.

If a SACPG system is a combined heat and power generation system, the basic standard coal consumption rate by its baseline unit can be selected in the literature [33], and the calculation of the $\eta_{b r, s c a a l, y}$ of its baseline unit has to follow the procedure described in Section 3.1.

\section{Conclusions}

A SACPG system can use solar thermal energy and reduce coal consumption and $\mathrm{CO}_{2}$ emissions, and it may be a promising generation technology. It can be built from a coal-fired power unit with solar energy integration. However, it is difficult to determine the output electricity, respectively, from solar energy and coal because of the operational complexity of the hybrid system. In this paper, a methodology for the output electricity allocation in a SACPG system and its $\mathrm{CO}_{2}$ emission reduction assessment is proposed on the basis of the operation analysis of the solar-coal hybrid system, its boundary and the government regulation.

In the methodology, the coal-to-electricity efficiency, $\eta_{b r, s c o a l, y}$, of the baseline unit or the coal-fired power system in a SACPG system is the key factor. Based on the Chinese government document, the norm of energy consumption per unit product of general coal-fired power set, the $\eta_{b r, s c o a l, y}$ can be calculated according to the procedure in Section 3.1, and it can also indicate the top operating efficiency of the coal-fired units in the grid and the potential for improving the efficiency of the coal-fired power system in the SACPG system. The methodology can simplify the calculation of the output electricity allocation in the solar-coal hybrid system, and it may provide incentives to improve the efficiency of its coal-fired power system or the integration of solar energy, and also to encourage SACPG systems to be built in solar-rich areas.

After $\eta_{b r, s c a l, y}$ is determined, the output electricity allocation in a SACPG system and its $\mathrm{CO}_{2}$ emission reductions can be calculated. The coal-to-electricity efficiency improvement of the coal-fired system in the SACPG system and the solar energy integration can be promoted through the analysis and adjustment of $\eta_{b r, s c o a l, y}$, which can guarantee that the calculation of $\mathrm{CO}_{2}$ emission reductions is accurate, conservative and transparent. According to the methodology, a 600 MW SACPG system, in which the first stage extraction steam with high pressure and temperature is substituted by solar heat, is taken as an example to determine the output electricity allocation and $\mathrm{CO}_{2}$ emission reduction evaluation. The results of the annual output electricity from solar energy and coal can be easily calculated, and they are, respectively, 47.781 and $3552.219 \mathrm{GWh}$. The $\mathrm{CO}_{2}$ emission reductions can also be easily calculated, and the result is $40,912.81 \mathrm{tCO}_{2}$.

On the basis of the output electricity allocation in a SACPG system and its $\mathrm{CO}_{2}$ emission reductions assessment, the hybrid system may acquire subsidies or financial support granted to renewable electricity and $\mathrm{CO}_{2}$ emission reductions. The methodology proposed in this paper can simplify the analysis of the allocation and assessment, and it can also provide incentives to improve the energy efficiency of a SACPG system and the integration of solar thermal energy. This methodology would provide theoretical references for policy-makers to make fair incentive policies and measures 
for utilizing solar energy and improving the coal-to-electricity efficiency of the coal-fired power system in a SACPG system.

Author Contributions: J.Z. and K.Y. conceived the theory; J.Z. built the model, performed the experiments, analyzed the data, and wrote the paper. All authors have read and agreed to the published version of the manuscript.

Funding: This research was funded by the Fundamental Research Funds for the Central Universities, grant number 11MR19.

Acknowledgments: The authors thank the anonymous reviewers for their helpful suggestions and comments, which improved this work. The responsibility for the contents lies with the authors.

Conflicts of Interest: The authors declare no conflict of interest.

\section{Appendix A}

Table A1. Basic standard coal consumption rate by a coal-fired unit [26].

\begin{tabular}{cccc}
\hline & $\begin{array}{c}\text { Capacity } \\
(\mathbf{M W})\end{array}$ & $\begin{array}{c}\boldsymbol{b}_{\mathbf{s , c o a l}} \text { of a New Unit } \\
(\mathbf{g} / \mathbf{k W h})\end{array}$ & $\begin{array}{c}\boldsymbol{b}_{\boldsymbol{s , c o a l}} \text { of a Unit on Active Duty } \\
(\mathbf{g} / \mathbf{k W h})\end{array}$ \\
\hline Ultra-supercritical units & 1000 & $\leq 279$ & $\leq 285$ \\
& 600 & $\leq 283$ & $\leq 293$ \\
Supercritical units & 600 & $\leq 295$ & $\leq 300$ \\
& 300 & $\leq 295$ & $\leq 308$ \\
Subcritical units & 600 & $\leq 295$ & $\leq 314$ \\
& 300 & $\leq 295$ & $\leq 323$ \\
\hline
\end{tabular}

Table A2. Modified coefficients for the cooling system of coal-fired units [26].

\begin{tabular}{cc}
\hline Type & $m_{\text {bcool }}$ \\
\hline Water-cooling system & 1.01 \\
Direct air-cooling system & 1.04 \\
Indirect air-cooling system & 1.05 \\
\hline
\end{tabular}

\section{References}

1. Davidson, M.R.; Zhang, D.; Xiong, W.M.; Zhang, X.L.; Karplus, V.J. Modelling the potential for wind energy integration on China's coal-heavy electricity grid. Nat. Energy 2016, 1, 7. [CrossRef]

2. China Electricity Council (CEC). China Power Industry Development Report; China Building Material Press: Beijing, China, 2019; pp. 88-91.

3. Mitchell, C. Momentum is increasing towards a flexible electricity system based on renewables. Nat. Energy 2016, 1, 6. [CrossRef]

4. Wu, J.; Hou, H.; Yang, Y.; Hu, E. Annual performance of a solar aided coal-fired power generation system (SACPG) with various solar field areas and thermal energy storage capacity. Appl. Energy 2015, 157, 123-133. [CrossRef]

5. Wu, J.; Hou, H.; Yang, Y. Annual economic performance of a solar-aided 600MW coal-fired power generation system under different tracking modes, aperture areas, and storage capacities. Appl. Therm. Eng. 2016, 104, 319-332. [CrossRef]

6. Hu, E.; Yang, Y.; Nishimura, A.; Yilmaz, F.; Kouzani, A. Solar thermal aided power generation. Appl. Energy 2010, 87, 2881-2885. [CrossRef]

7. Zhai, R.; Liu, H.; Li, C.; Zhao, M.; Yang, Y. Analysis of a solar-aided coal-fired power generation system based on thermo-economic structural theory. Energy 2016, 102, 375-387. [CrossRef]

8. Zhu, Y.; Zhai, R.; Qi, J.; Yang, Y.; Reyes-Belmonte, M.A.; Romero, M.; Yan, Q. Annual performance of solar tower aided coal-fired power generation system. Energy 2017, 119, 662-674. [CrossRef]

9. Peng, S.; Hong, H.; Wang, Y.; Wang, Z.; Jin, H. Off-design thermodynamic performances on typical days of a 330MW solar aided coal-fired power plant in China. Appl. Energy 2014, 130, 500-509. [CrossRef] 
10. Yang, Y.; Yan, Q.; Zhai, R.; Kouzani, A.; Hu, E. An efficient way to use medium-or-low temperature solar heat for power generation-Integration into conventional power plant. Appl. Therm. Eng. 2011, 31, 157-162. [CrossRef]

11. You, Y.; Hu, E.J. A medium-temperature solar thermal power system and its efficiency optimisation. Appl. Therm. Eng. 2002, 22, 357-364. [CrossRef]

12. Zhai, R.; Zhao, M.; Tan, K.; Yang, Y. Optimizing operation of a solar-aided coal-fired power system based on the solar contribution evaluation method. Appl. Energy 2015, 146, 328-334. [CrossRef]

13. Zoschak, R.J.; Wu, S.F. Studies of the direct input of solar energy to a fossil-fueled central station steam power plant. Sol. Energy 1975, 17, 297-305. [CrossRef]

14. Siva Reddy, V.; Kaushik, S.C.; Ranjan, K.R.; Tyagi, S.K. State-of-the-art of solar thermal power plants-A review. Renew. Sustain. Energy Rev. 2013, 27, 258-273. [CrossRef]

15. Zhou, L.; Li, Y.; Hu, E.; Qin, J.; Yang, Y. Comparison in net solar efficiency between the use of concentrating and non-concentrating solar collectors in solar aided power generation systems. Appl. Therm. Eng. 2015, 75, 685-691. [CrossRef]

16. Hou, H.; Wu, J.; Yang, Y.; Hu, E.; Chen, S. Performance of a solar aided power plant in fuel saving mode. Appl. Energy 2015, 160, 873-881. [CrossRef]

17. Lozano, M.A.; Valero, A. Theory of the exergetic cost. Energy 1993, 18, 939-960. [CrossRef]

18. Yang, M.-H.; Yeh, R.-H. Thermo-economic optimization of an organic Rankine cycle system for large marine diesel engine waste heat recovery. Energy 2015, 82, 256-268. [CrossRef]

19. Beretta, G.P.; Iora, P.; Ghoniem, A.F. Allocating electricity production from a hybrid fossil-renewable power plant among its multi primary resources. Energy 2013, 60, 344-360. [CrossRef]

20. Reyes-Belmonte, M.A.; Sebastián, A.; Romero, M.; González-Aguilar, J. Optimization of a recompression supercritical carbon dioxide cycle for an innovative central receiver solar power plant. Energy 2016, 112, 17-27. [CrossRef]

21. Lin, R.; Han, W.; Jin, H.; Zhao, Y. The integrated solar combined cycle power generation systems. Gas Turbine Technol. 2013, 2, 1-15.

22. Hou, H.-j.; Yu, Z.-y.; Yang, Y.-p.; Chen, S.; Luo, N.; Wu, J. Performance evaluation of solar aided feedwater heating of coal-fired power generation (SAFHCPG) system under different operating conditions. Appl. Energy 2013, 112, 710-718. [CrossRef]

23. Morin, G.; Dersch, J.; Platzer, W.; Eck, M.; Häberle, A. Comparison of Linear Fresnel and Parabolic Trough Collector power plants. Sol. Energy 2012, 86, 1-12. [CrossRef]

24. Manzolini, G.; Bellarmino, M.; Macchi, E.; Silva, P. Solar thermodynamic plants for cogenerative industrial applications in southern Europe. Renew. Energy 2011, 36, 235-243. [CrossRef]

25. Zhao, Y.; Hong, H.; Jin, H. Mid and low-temperature solar-coal hybridization mechanism and validation. Energy 2014, 74, 78-87. [CrossRef]

26. Standardization Administration. The Norm of Energy Consumption per Unit Product of General Coal-Fired Power Set. Available online: http://www.cspress.com.cn/biaozhunziliao/1553.html (accessed on 11 May 2019).

27. CDM Executive Board, Energy Efficiency Improvements of a Power Plant Through Retrofitting Turbines. Available online: https://cdm.unfccc.int/methodologies/DB/OKL41FKIXKLBV1A91SPV0HYJZGDFJX (accessed on 11 May 2019).

28. Liu, D. Revision to the Approved Consolidated Baseline Methodology ACM0002. Available online: http: //cdm.ccchina.org.cn/UpFile/File621.PDF (accessed on 10 May 2019).

29. Dudley, V.E.; Kolb, G.; Mahoney, A.R.; Mancini, T.R.; Matthews, C.W.; Sloan, M.; Kearney, D. Test results: SEGS LS-2 solar collector. Other Information: PBD: December 1994. Available online: https://www.osti.gov/ servlets/purl/70756 (accessed on 11 October 2019).

30. Zhang, Y. Research on Solar-Coal Hybrid Electricity Generation System; North China Electric Power University: Beijing, China, 20 December 2007.

31. National Energy Administration (NEA). Energy Saving and Emission Reduction Upgrade and Retrofit Action Plan for Coal-Fired Power Units (2014-2020). Available online: http://zfxxgk.nea.gov.cn/auto84/ 201409/t20140919_1840.htm (accessed on 21 May 2019). 
32. The National Development and Reform Commission (NDRC). China's Regional Grid Baseline Emission Factors in 2017. Available online: http://qhs.mee.gov.cn/kzwsqtpf/201812/P020181220579925103092.pdf (accessed on 25 May 2019).

33. Standardization Administration. The Norm of Energy Consumption per Unit Product of Combined Heat and Power Generation. Available online: http://www.cspress.com.cn/biaozhunziliao/40862.html (accessed on 12 May 2019).

(c)

(C) 2020 by the authors. Licensee MDPI, Basel, Switzerland. This article is an open access article distributed under the terms and conditions of the Creative Commons Attribution (CC BY) license (http://creativecommons.org/licenses/by/4.0/). 